\title{
Standardised patient education in adrenal insufficiency: a prospective multi-centre evaluation
}

\author{
Stephanie Burger-Stritt ${ }^{1, *}$, Annemarie Eff1,*, Marcus Quinkler², Tina Kienitz ${ }^{3}$, Bettina Stamm4, \\ Holger S Willenberg ${ }^{5}$, Gesine Meyer ${ }^{6}$, Johannes Klein${ }^{7}$, Nicole Reisch ${ }^{8}$, Michael Droste ${ }^{9}$ and Stefanie Hahner ${ }^{1}$
}

${ }^{1}$ Endocrinology and Diabetes Unit, Department of Medicine I, University Hospital Wuerzburg, Wuerzburg, Germany, ${ }^{2}$ Endocrinology in Charlottenburg, Berlin, Germany, ${ }^{3}$ Department of Endocrinology, Diabetes and Nutrition, Charité - Universitätsmedizin Berlin, corporate member of Freie Universität Berlin, Humboldt-Universität zu Berlin, and Berlin Institute of Health, Berlin, Germany, ${ }^{4}$ Medical practice for Endocrinology, Saarbrücken, Germany, ${ }^{5}$ Division of Endocrinology and Metabolism, Rostock University Medical Center, Rostock, Germany, ${ }^{6}$ Endocrinology \& Diabetes Unit, Department of Internal Medicine 1, GoetheUniversity Hospital Frankfurt, Frankfurt/Main, Germany, ${ }^{7}$ Medical Practice for Endocrinology, Lübeck, Germany, ${ }^{8}$ Medizinische Klinik IV, Klinikum der Universität München, Munich, Germany, and ${ }^{9}$ Medical Practice for Endocrinology \& Diabetes, Oldenburg, Germany

\begin{abstract}
Objective: Patients with adrenal insufficiency (Al) suffer from impaired quality of life and are at risk of adrenal crisis (AC) despite established replacement therapy. Patient education is regarded an important measure for prevention of $A C$ and improvement of Al management. A standardized education programme was elaborated for patients with chronic Al in Germany.

Design: Longitudinal, prospective, questionnaire-based, multi-centre study.

Methods: During 2-h sessions, patients $(n=526)$ were provided with basic knowledge on Al, equipped with emergency cards and sets and trained in self-injection of hydrocortisone. To evaluate the education programme, patients from eight certified centres completed questionnaires before, immediately after and 6-9 months after training. Results: 399 completed data sets were available for analysis. Questionnaire score-values were significantly higher after patient education, indicating successful knowledge transfer (baseline: $17 \pm 7.1$ of a maximum score of 29; after training: $23 \pm 4.2 ; P<0.001$ ), and remained stable over $6-9$ months. Female sex, younger age and primary cause of Al were associated with higher baseline scores; after education, age, cause of Al and previous adrenal crisis had a significant main effect on scores. $91 \%$ of patients would dare performing self-injection after training, compared to $68 \%$ at baseline. An improvement of subjective well-being through participation in the education programme was indicated by $95 \%$ of the patients 6-9 months after participation.

Conclusion: Patient group education in chronic Al represents a helpful tool for the guidance of patients, their selfassurance and their knowledge on prevention of adrenal crises. Repeated training and adaptation to specific needs, for example, of older patients is needed.
\end{abstract}




\section{Introduction}

In patients with chronic adrenal insufficiency (AI), reduced quality of life and increased morbidity and mortality is well documented and has largely been attributed to inadequate hormone replacement $(1,2,3$, $4,5,6,7,8,9,10,11,12,13,14)$. Adequate management of AI by the individual patient is thus essential for maintenance of general well-being and daily life activities as well as protection from adrenal emergencies $(15,16)$. The specific difficulties usually associated with a rare disease, such as reduced awareness and limited experience in their management by health professionals, further emphasize the important role of a well-educated patient $(17,18,19,20)$.

According to current guidelines, patients with AI need to be equipped with an emergency card and set. They should furthermore be educated in glucocorticoid (GC) dose-adjustment to cover the increased need in case of stressful events (16). Besides oral dose adjustment during mild and moderate stress, parenteral GC administration for example, in case of gastroenteritis or fever is of high importance (15). In a large survey, AC occurred away from home or health care facilities in $>20 \%$ (21). Patient education opens up the possibility for AI patients to act rapidly and independently in emergency situations until professional help is provided. However, education is so far not standardized and varies between centres. Two studies revealed that only $30 \%$ of the investigated AI patients were equipped with emergency medication such as GC suppositories or GC ampules $(9,13)$. Moreover, only $64 \%$ of the patients felt 'very well' or 'well' informed about crisis prevention and GC dose adaptation (13). Another study documented that more than $60 \%$ of AI patients were dissatisfied with the received information on their hormone replacement therapy and that more than 50\% had concerns regarding their replacement therapy with GCs (22). This is of relevance for the patients' well-being as stronger concerns about adverse effects of GCs were associated with more negative illness perceptions (23).

Flemming et al. demonstrated that $46 \%$ of 97 interviewed patients with chronic AI were not sufficiently skilled in coping with stress, supporting the view that more structured education is needed (24). Furthermore, a positive effect of written instructions and demonstration of injection techniques on the management of AC in children was observed (25). Repping-Wuts et al. showed that the participation in a 3-h GC education group meeting improved the patients' knowledge about emergency management in a single-centre study (26).
Recently, nine German endocrine centres established a standardized education programme for patients with AI. Meanwhile, more than 70 centres were certified by the German Endocrine Society and regularly offer this form of education to their patients. The aim of our study was to evaluate this standardized patient education programme at the initiating centres with a focus on the improvement and maintenance of patient knowledge and the feeling of safety regarding the management of adrenal emergencies.

\section{Subjects and methods}

\section{Study design}

The study was conducted as a prospective, longitudinal, multicentre and questionnaire-based study. Patients from eight centres were included: University Hospital Wuerzburg, a medical practice for endocrinology in Oldenburg, a medical practice for endocrinology in Berlin, the University Hospital Berlin (Charité), the University Hospital Frankfurt, the University Hospital Rostock, a medical practice in Saarbruecken and a medical practice in Luebeck. Patients aged $\geq 18$ years with documented AI under established corticosteroid replacement therapy who participated in the standardized patient education were invited to participate in the evaluation. The study was approved by the Ethics Committees of the Universities of Wuerzburg (permit no.278/14), Charité Berlin (permit, following approval of Wuerzburg), Rostock (permit no. A2016-0088) and Frankfurt (permit no. 283/15). Clinicaltrials.gov identifier: NCT02694926. Written informed consent was obtained from all patients prior participation.

\section{Standardized patient education}

All study centres had been certified by the German Endocrine Society for the education programme within a 1-day certification course. The centres used the same training material including a power-point presentation that had been elaborated and consented by all participating centres. The patient education consisted of a 2-h group training for patients and their relatives (4-10 participants per session). The participants received background information on adrenal physiology and AI in general. Furthermore, knowledge on dose adjustment of GCs during physical or psychological stress, AC, emergency management and self-injection of hydrocortisone including a practical training was provided by an endocrine 
nurse together with an endocrinologist (Supplementary data, see section on supplementary materials given at the end of this article). Patients had the opportunity to ask questions and exchange personal experience with their disease. They were invited to perform an i.m. or off-label s.c. self-injection by themselves under medical supervision. In the end, all patients were equipped with an emergency card and material required for parenteral hydrocortisone administration together with written information on AI, dose adjustment and i.m. self-injection.

\section{Questionnaire}

To evaluate the education programme, all participants received a questionnaire at baseline before (Q1), immediately (Q2) and 6-9 months after education (Q3). Q3 was provided either by postal service or at presentation for a follow-up appointment. The questionnaire consisted of two parts: (i) Questions on the individual course and perception of $\mathrm{AI}$, (ii) test of knowledge on $\mathrm{AI}$ and AC. The first part included questions on the availability of an emergency card and set, previous education in selfinjection, previous self-injection during an emergency situation, perceived influence of a standardized education on quality of life, information status on AI and dose adjustment, feeling of safety (education status) in GC dose adaptation and self-injection, confidence to perform a self-injection, self-assessment of the ability to estimate AC and to deal with AC (only Q2 and Q3). The patients had to rate from ' $1=$ very good/assured' to ' $5=$ very bad/ unsure' (Scale 1-5) for the following items: Self-assessment of the patients' information status on AI, dose adaptation, self-injection, self-assessment of the ability to recognize $\mathrm{AC}$ and self-assurance to deal with incident AC. Lower scores, therefore, imply a higher degree of self-assurance. The second part of the questionnaire was a knowledge test (maximum achievable score 29) including questions on AI in general as well as on dose adaptation (maximum sub-score: 19) and emergency management (maximum sub-score: 10). Higher questionnaire scores indicate a higher level of knowledge.

\section{Statistical analysis}

Statistical analysis was performed by PASW Statistics 24 (IBM SPSS, IBM Corp.). For comparison of scores, a repeated-measures ANOVA with Bonferroni correction was used. Bonferroni and Dunnet-T3 procedure were used as post hoc tests. For group comparison of scores an unpaired $t$-test (two groups, e.g. sex) or one-way ANOVA with Bonferroni and Dunnet-T3 procedure as post hoc tests (>two groups, e.g. cause of AI) were used. To evaluate the main effects of sex, age, cause of AI, duration of disease and history of a previous $\mathrm{AC}$ as well as the interaction effects of these variables on the scores, a (multivariate) factorial ANOVA was performed. For comparison of questions between two points in time, a paired $t$-test was used for metric variables. $\chi^{2}$ test, Fischer's exact test or a generalised estimating equation (GEE) was used for comparison of categorical variables. Furthermore, Pearson correlation was performed to correlate metric variables with a Gaussian distribution. Data are presented as mean and standard deviation (s.D.) or median and range. Differences were considered as statistically significant when $P<0.05$.

\section{Results}

\section{Study cohort}

526 patients with AI agreed to participate. 127 patients completed only two questionnaires (before and directly after education); 399 patients completed all three questionnaires and were included in the final analysis. Patient characteristics are displayed in Table 1.

Before education, $59 \%$ of the patients indicated that they are doing 'very well' or 'well' regarding AI in general, $33 \%$ rated 'satisfying' and $7.9 \%$ 'bad' or 'very bad'. $66 \%$ of the patients stated that their private life and $54 \%$ of the employed patients that their professional life was affected by AI.

\section{Evaluation of theoretical training}

Total scores as well as the sub-scores of the knowledgetest significantly increased after patient education (all $P<0.001)$ and remained stable after 6-9 months indicating successful knowledge transfer. Total score: Q1: $17 \pm 7.1$, Q2: $23 \pm 4.2$ and Q3: $23 \pm 4.1$; Fig. 1A. Sub-score AI/dose adaptation: Q1: $11 \pm 4.9, \mathrm{Q} 2: 14 \pm 3.1$ and Q3: $14 \pm 3$.1; Fig. 1B. Sub-score AC/emergency-management: Q1: $6.7 \pm 2.8$, Q2: $8.7 \pm 1.7$ and Q3: 8.6 \pm 1.6 ; Fig. 1C.

The total score at baseline (Q1) correlated negatively with age $(r=-0.320, P<0.001)$ but positively with the duration of disease $(r=0.110, P=0.028)$. After education, the total score again correlated negatively with age $(\mathrm{Q} 2$ $r=-0.340, \quad P<0.001 ;$ Q3 $r=-0.320, P<0.001)$, but no longer with the duration of disease.

Patients with primary AI, younger patients (at/ below the median age of 55 years) and patients with 
Table 1 Characteristics of participating patients with a complete set of questionnaires.

\begin{tabular}{l}
\hline \\
\hline Cause of $\mathrm{Al}$ \\
Primary $\mathrm{Al}(n)$ \\
Secondary $\mathrm{Al}(n)$ \\
latrogenic $\mathrm{Al}(n)$ \\
Unknown origin of Al $(n)$ \\
Age (years) \\
Duration of disease (years) \\
Previous AC* (\%) \\
Emergency card available* (\%) \\
Emergency set available* (\%) \\
Previous education in GC-injection* (\%)
\end{tabular}

\begin{tabular}{c}
\hline Total $(n=399)$ \\
\hline 163 \\
225 \\
7 \\
4 \\
$55(18-85)$ \\
$6(0-64)$ \\
23 \\
83 \\
47 \\
14 \\
\hline
\end{tabular}

\begin{tabular}{c}
\hline Female $(n=236)$ \\
\hline 116 \\
112 \\
5 \\
3 \\
$54(18-85)$ \\
$6(0-64)$ \\
26 \\
85 \\
54 \\
15 \\
\hline
\end{tabular}

\begin{tabular}{c}
\hline Male $(n=163)$ \\
\hline 47 \\
113 \\
2 \\
1 \\
$58(19-81)$ \\
$5(0-41)$ \\
18 \\
79 \\
37 \\
11
\end{tabular}

*Before standardized education. Age and duration of disease are displayed as median and range.

AC, adrenal crisis; Al , adrenal insufficiency; GC, glucocorticoid.

a previous AC had significantly higher scores both at baseline and after education compared to secondary AI, older patients (>55 years) and patients without a history of an AC (Table 2). Female patients had significantly higher scores both before and 6-9 months after education (Table 2).

To compare the main effects of sex, age, cause of AI, duration of disease and history of a previous AC as well as interaction effects between these variables on the scores in Q1, Q2 and Q3, a factorial ANOVA was performed. At baseline (Q1), sex $(\mathrm{F}=4.1, P=0.044)$, age $(\mathrm{F}=25.3, P<0.001)$ and cause of $\mathrm{AI}(\mathrm{F}=29.9, P<0.001)$ had a significant main effect on the score values, with higher values in females, patients $\leq 55$ years as well as patients with primary AI. After education, age $(\mathrm{Q} 2 \mathrm{~F}=44.1$ and Q3 $\mathrm{F}=19.7$, each
$P<0.001)$ and cause of AI (Q2 F=11.0, $P=0.001$ and Q3 $\mathrm{F}=14.7, P<0.001)$ had a significant main effect on scores with still higher score values in patients $\leq 55$ years and patients with primary AI. Moreover, in Q3, history of an AC had a significant main effect on the score $(F=7.1$; $P=0.008$ ) with higher values in patients with a previous AC. Before education (Q1), significant interaction effects between disease duration and age $(\mathrm{F}=13.0, P<0.001)$ as well as cause of $\mathrm{AI}(\mathrm{F}=16.3, P<0.001)$ and between previous AC and cause of $\mathrm{AI}(\mathrm{F}=16.4, P<0.001)$ as well as age $(\mathrm{F}=12.8, P \leq 0.001)$ were seen. Directly after education (Q2), we observed significant interaction effects between history of an AC and cause of $\mathrm{AI}(\mathrm{F}=6.5, P=0.002)$ as well as age $(\mathrm{F}=22.2, P<0.001)$. In $\mathrm{Q} 3$, significant interaction effects between sex and age $(F=11.7, P<0.001)$, cause of
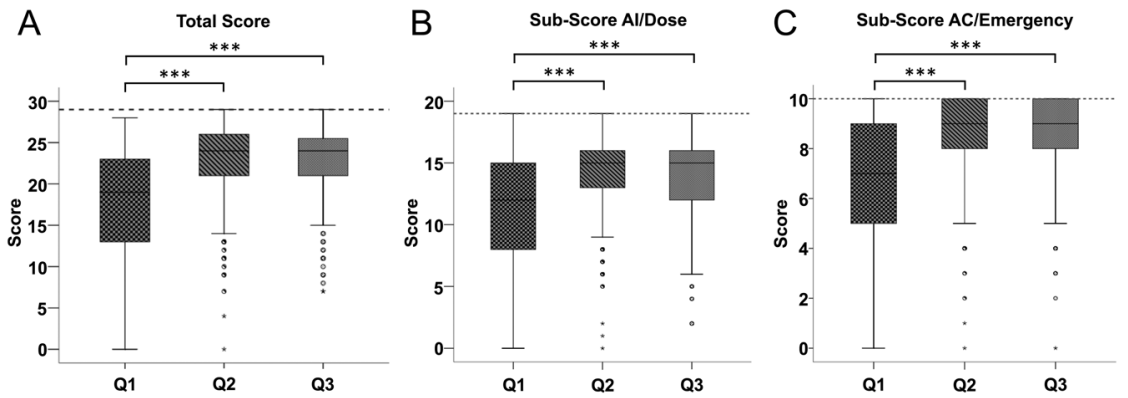

\section{Figure 1}

Score values of the test of knowledge before (Q1), directly after (Q2) and 6-9 months after (Q3) standardized patient education. (A) Total score values ( maximum achievable total score $=29$ ). (B) Sub-score including general questions about adrenal insufficiency (Al) and dose adaptation (maximum sub-score $=19$ ). (C) Sub-score including questions about adrenal crisis (AC) and emergency management (maximum sub-score $=10$ ). The dotted lines indicate the maximum possible score values. Higher questionnaire scores indicate a higher level of knowledge. Analyses were performed by repeated measure ANOVA; $\star \star * P<0.001$. 
Table 2 Comparison of total scores (test of knowledge) dependent on sex, age, cause of adrenal insufficiency (Al), duration of disease and previous adrenal crisis (AC), before (Q1), directly after (Q2) and 6-9 months after (Q3) patient education.

\begin{tabular}{|c|c|c|c|c|}
\hline & $n$ & Score - Q1 & Score - Q2 & Score-Q3 \\
\hline \multicolumn{5}{|l|}{ Sex } \\
\hline Female & 236 & $19 \pm 6.8$ & $23 \pm 4.4$ & $23 \pm 4.3$ \\
\hline Male & 163 & $16 \pm 7.3$ & $23 \pm 3.9$ & $22 \pm 3.7$ \\
\hline$P$ value & & $<0.001$ & 0.054 & 0.033 \\
\hline \multicolumn{5}{|l|}{$\mathrm{Al}$} \\
\hline Primary & 163 & $20 \pm 6$ & $24 \pm 3.2$ & $24 \pm 3.2$ \\
\hline Secondary & 225 & $15 \pm 7.3$ & $22 \pm 4.6$ & $22 \pm 4.4$ \\
\hline$P$ value & & $<0.001$ & $<0.001$ & $<0.001$ \\
\hline \multicolumn{5}{|l|}{ Age } \\
\hline$\leq 55$ years & 202 & $20 \pm 6.1$ & $24 \pm 3$ & $24 \pm 3.3$ \\
\hline$>55$ years & 197 & $15 \pm 7.4$ & $22 \pm 4.7$ & $21 \pm 4.4$ \\
\hline$P$ value & & $<0.001$ & $<0.001$ & $<0.001$ \\
\hline \multicolumn{5}{|l|}{ Duration of $\mathrm{Al}$} \\
\hline$\leq 10$ years & 261 & $17 \pm 7.5$ & $23 \pm 4.1$ & $23 \pm 4.1$ \\
\hline$>10$ years & 136 & $18 \pm 6.2$ & $23 \pm 4.4$ & $23 \pm 3.9$ \\
\hline$P$ value & & 0.031 & 0.702 & $0 . \overline{7} 89$ \\
\hline \multicolumn{5}{|l|}{ Previous AC } \\
\hline No & 223 & $17 \pm 7.2$ & $23 \pm 4.2$ & $22 \pm 4.1$ \\
\hline Yes & 90 & $20 \pm 6$ & $24 \pm 4.2$ & $24 \pm 3.1$ \\
\hline$P$ value & & $<0.001$ & 0.007 & $<0.001$ \\
\hline
\end{tabular}

Results are displayed as mean \pm S.D. Analyses were performed by unpaired $t$-test. Differences were considered as statistically significant when $P<0.05$ and are printed in bold. Maximum achievable total score $=29$.

Q, questionnaire.

AI $(\mathrm{F}=8.1, P<0.001)$ as well as history of an AC $(\mathrm{F}=3.9$, $P=0.021)$ on score values were documented.

\section{Patients' self-assessment of information status}

In Q2 and Q3, patients rated their general information status on AI and dose adaptation as well as their assurance in dose adaptation as improved compared to the baseline assessment. However, self-assessment of information status showed significantly worse scores in Q3 compared to Q2 after education (Fig. 2).

Disease duration correlated negatively with the selfassessment score regarding the information status on AI $(r=-0.184, P<0.001)$ and dose adaptation $(r=-0.187$, $P<0.001)$ before education, indicating that patients with longer disease duration felt better informed (lower score values represent better self-assessment). Disease duration furthermore showed negative correlation with the selfassurance score on dose adaptation at baseline $(r=-0.202$, $P<0.001)$, Q2 $(r=-0.161, P=0.002)$ and Q3 $(r=-0.144$, $P=0.005$ ) (again, lower scores imply higher self-assurance). Patients' self-assessment did not differ between males and

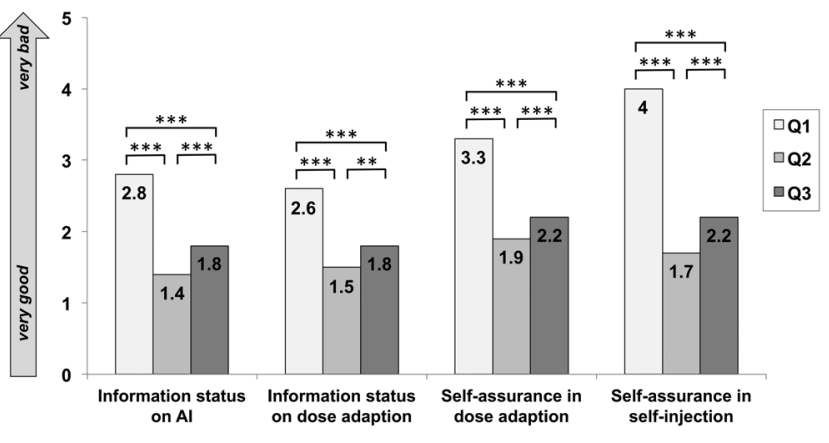

Figure 2

Comparison of patients' self-assessment of the information status on $\mathrm{Al}(n=362)$, information status on dose adaptation $(n=360)$, assurance in dose adaptation $(n=334)$ and assurance in self-injection ( $n=298$ ) before (Q1) after (Q2) and 6-9 months after (Q3) standardized patient education. The scale ranges from ' 1 = very good' to ' 5 = very bad'. Lower scores imply better self-assessment. Analyses were performed by repeatedmeasures ANOVA; $* * * P<0.001, * * P=0.001$.

females at any time point. Also, no differences between patients with primary and secondary AI were observed.

\section{Self-perceived influence on quality of life}

At baseline (Q1), 94\% of patients were of the opinion that a standardized patient education would improve their quality of life. This increased at follow up: Q2 98\% and Q3 95\%. (Q2 versus Q1 $P=0.004$; Q2 versus Q3 $P=0.023)$.

\section{Patient self-assessment - GC self-injection}

After participation, significantly more patients stated that they would dare to perform a self-injection compared to baseline evaluation before education: Q1 68\%, Q2 91\%, Q3 83\%; $P<0.001$, respectively. However, significantly fewer patients would dare to perform a self-injection 6-9 months after compared to directly after education indicating a loss of self-assurance over this time interval, Fig. 3A. Younger patients were more confident to selfinject compared to older patients both at baseline and long-term follow-up (Fig. 3D). Furthermore, more male patients rated that they would dare to self-inject compared to females in Q1 and Q2 (Fig. 3B). At baseline, the number of patients that would dare to perform a self-injection was higher in secondary compared to primary AI, whereas after education no significant difference was observed any more (Fig. 3C). 

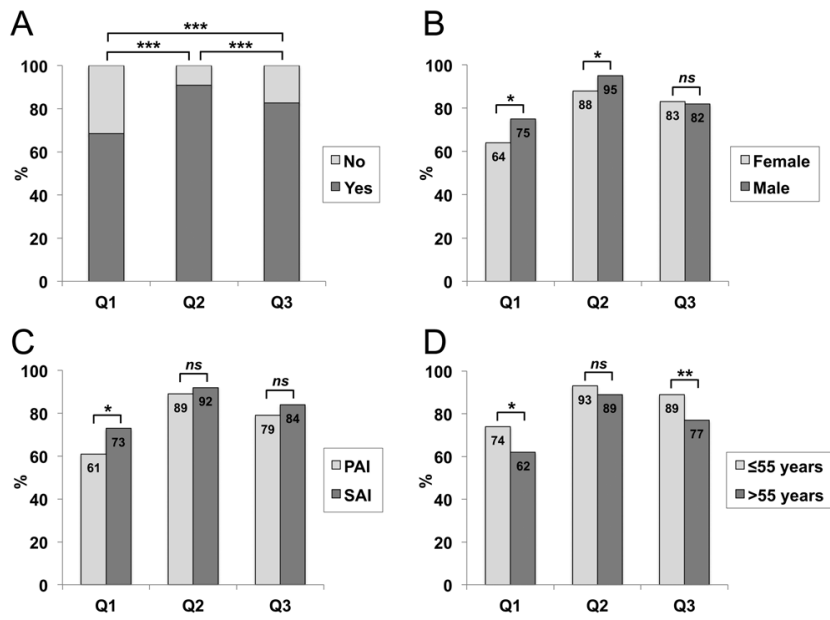

Figure 3

Percentage of patients who would dare to perform a selfinjection before (Q1), directly after (Q2) and 6-9 months after (Q3) patient education (A); dependent on sex (B), cause of $A I$ $(C)$ and age (D). Analyses were performed by generalised estimating equation $(A)$ or $\chi^{2}$ test $(B, C$ and $D)$; $* \star * P<0.001$, ** $P<0.01, * P<0.05$, ns (not significant).

\section{Patients' self-assessment - adrenal crisis}

The self-assessment regarding the recognition of signs and symptoms of incipient AC was significantly better in Q2 compared to Q3 $(2.2 \pm 0.7$ versus $2.5 \pm 0.9, P<0.001)$. Furthermore, patients felt better prepared to manage an AC in Q2 compared to Q3 $(2.2 \pm 0.8$ versus $2.6 \pm 0.9$, $P<0.001)$. The scores did not differ significantly between female and male patients or primary, secondary and iatrogenic AI at any time-point.

\section{Discussion}

An important finding of our study is the lasting gain in knowledge on management of $\mathrm{AI}$ and $\mathrm{AC}$ and the increased self-confidence to manage AC after participation in our standardized group education programme. This certainly provides an important basis for improved prevention of AC. Data from a large survey in patient support groups from UK, performed in 2013 and 2017/18, showed an increased use of self-injection and more frequent AC treatment in a timely manner in a pre-hospital setting over the 5-year interval which was attributed to a broader availability of information on management of AC in the UK (21). Similarly, we recently found improved time intervals and a higher rate of out-patient emergency treatment in a prospective analysis of AI patients. Of these patients, $71 \%$ had already participated in our standardized education programme (20).

Several differences between patient sub-groups were observed that may be relevant for adaptation of teaching concepts. Both at baseline and after 6-9 months, mean knowledge scores were lower in males, older patients, patients with secondary AI and patients without history of previous AC. Investigations on risk factors for AC revealed that primary AI, diabetes insipidus, concomitant nonendocrine disease, female sex and those with a history of AC were more prone to develop an AC $(9,12,13,27)$. Patients who had already experienced an AC were more proactive with regard to GC dose adjustments in case of fever in a previous study (9). This fits to our observation that patients with a history of AC in the past also achieved higher total scores in the test of knowledge both at baseline and after standardized group education. It may be assumed that these patients already were more aware of complications of AI and aimed at a higher information status. Attending physicians may furthermore have invested more time in individual patient education after an AC. Remarkably, data from the European Adrenal Insufficiency Registry revealed a higher mortality risk in older male patients with secondary AI and comorbidity, the group representing those patients in our study who presented with a lower level of knowledge on their disease (28). The increased mortality in this group was in part be related to inadequate management of replacement therapy (28).

An increase of hospital admissions due to AC with advancing age, mainly associated with an increased incidence of infectious disease, was observed in an Australian analysis (29). In our study, older patients achieved significantly lower total scores both before and after group education compared to younger study participants. They were furthermore less confident to self-inject. This leads to the consideration of more specific or at least more frequently repeated training for older patients. Based on empirical observations from our education programme, preparation of the hydrocortisone syringes was frequently overcharging particularly for older patients, which may have further contributed to reduced confidence. Tools facilitating emergency management would, therefore, be desirable.

Another finding of our study is that patients' selfassessment regarding the information status on $\mathrm{AI}$, dose adaptation as well as their assurance in self-management slightly worsened at 6-9 months compared to first testing after education. Moreover, significantly fewer patients would dare to perform a self-injection and patients felt 
less assured in the handling of an AC 6-9 months after compared to directly after education. Corresponding to this, van der Meij et al. observed that one or two educational consults are not sufficient to achieve lasting competence in self-management of stressful events in AI (30). Repetition of education in at least yearly intervals appears to be essential and should be recommended to the patients. In this context, an allocation in a basic and advanced patient education course may be helpful. This should be complemented by repetition of main educational messages during endocrine outpatient consultations or in case of hospital admission due to adrenal insufficiency. Furthermore, the use of additional tools like apps or online videos may help to sustain the patient's knowledge.

Remarkably, most patients of our study indicated that participation in a systematic training also improved their subjective well-being in general, indicating a so far unmet need of improved patient information.

Self-management of adrenal emergencies may bear the risk of delayed contacting of medical professionals in case of AC. Thus, it is important that education courses are led by trained medical professionals, who inform the patients that self-injection of GCs in case of an emergency must be followed by contacting a treating endocrinologist, emergency physician or a professional in general medicine.

Although a large number of AI patients has been evaluated within this prospective multicentre analysis, the study has some limitations: Since most patients completed the follow-up questionnaire 6-9 months after education at home, it cannot be excluded that they used the help of available written information on $\mathrm{AI}$ and $\mathrm{AC}$ or other persons (relatives) to answer the questions of the test resulting in higher scores. Using the available resources is, however, not necessarily a weakness since patients also have the possibility to use them in case of real adrenal emergencies. Patients were treated in centres that are specialized for the management of AI and may therefore have received more information already before inclusion in the training programme compared to patients from less specialized centres. Moreover, despite standardisation of group education as a basis of the programme and documented gain of knowledge in patients from all centres, at least minor variations between the study centres dependent on the educating medical professionals cannot be ruled out.

Further analyses focusing on outcome measures like frequency of $\mathrm{AC}$, hospitalization rate and mortality are needed in the long-term course to approve the benefit of patient education.
In conclusion, this prospective study demonstrates significant positive effects of a standardized groupeducation in AI by a large multicentre study. Structured and repeated patient education bears the potential of improving patient care, management of AC, self-assurance and subjective well-being in AI patients.

\section{Supplementary materials}

This is linked to the online version of the paper at https://doi.org/10.1530/ EJE-20-0181.

\section{Declaration of interest}

The authors declare that there is no conflict of interest that could be perceived as prejudicing the impartiality of this study.

\section{Funding}

This work was supported by the Deutsche Forschungsgemeinschaft (DFG) (within the CRC/Transregio 205/1 'The Adrenal: Central Relay in Health and Disease') to $S$ Hahner as well as a research grant to $S$ Burger-Stritt from the IZKF Wuerzburg (Project-No.: Z-2/62).

\section{Study group}

Wuerzburg: Stephanie Burger-Stritt, Annemarie Eff, Silke Horn, Walter Rüger, Alina Pulzer, Stefanie Hahner. Oldenburg: Michael Droste, Smadar Pahl, Jessica Norkeweit. Berlin-Charité: Tina Kienitz, Kathrin Zopf, Christiane Friedrich, Ulf Elbelt, Janina Kirchner. Berlin Charlottenburg: Markus Quinkler, Britta Bauer. Saarbruecken: Bettina Stamm, Marion Zeller. Frankfurt: Gesine Meyer, Maria Sandler. Rostock: Holger S. Willenberg, Andreas Knauerhase, Elena Novikova, Christiane Otte, Doreen Grube, Clemens Verbeek. Luebeck: Johannes Klein, Sandra Britt. Munich: Nicole Reisch.

\section{Author contribution statement}

$S$ Burger-Stritt was involved in the design of the study, preparation of study protocol, preparation of applications for authorities, conduct of the study, data analysis and preparation of the manuscript. A Eff was involved in the preparation of study protocol, preparation of applications for authorities, conduct of the study, data collection and data analysis. M Quinkler was involved in the design and conduct of the study. T Kienitz, B Stamm, H Willenberg, G Meyer, J Klein, N Reisch were involved in the conduct of the study. M Droste was involved in the design and conduct of the study. S Hahner was involved in the design of the study, preparation of study protocol and applications for authorities, conduct of the study and preparation of the manuscript. All authors reviewed and approved the manuscript.

\section{Acknowledgements}

The authors would like to thank all participating study-centres for their excellent cooperation as well as all participating patients. They particularly thank Silke Horn, Walter Rüger, Alina Pulzer (Würzburg), Smadar Pahl, Jessica Norkeweit (Oldenburg), Britta Bauer, Ulf Elbelt, Kathrin Zopf, Christiane Friedrich, Janina Kirchner (Berlin), Marion Zeller (Saarbrücken), Andreas Knauerhase, Elena Novikova, Christine Otte, Doreen Grube, Clemens Verbeek (Rostock), Maria Sandler (Frankfurt), and Sandra Britt (Lübeck) for their highly valuable support. they thank the department of 
epidemiology of the University of Wuerzburg as well as the epidemiology of the LMU Munich at UNIKA-T Augsburg for their statistical advice. The study was a project of the Section 'Nebenniere, Steroide und Hypertonus' of the German Endocrine Society (DGE).

\section{References}

1 Bergthorsdottir R, Leonsson-Zachrisson M, Oden A \& Johannsson G. Premature mortality in patients with Addison's disease: a populationbased study. Journal of Clinical Endocrinology and Metabolism 200691 4849-4853. (https://doi.org/10.1210/jc.2006-0076)

2 Bensing S, Brandt L, Tabaroj F, Sjoberg O, Nilsson B, Ekbom A, Blomqvist P \& Kampe O. Increased death risk and altered cancer incidence pattern in patients with isolated or combined autoimmune primary adrenocortical insufficiency. Clinical Endocrinology 200869 697-704. (https://doi.org/10.1111/j.1365-2265.2008.03340.x)

3 Erichsen MM, Lovas K, Fougner KJ, Svartberg J, Hauge ER, Bollerslev J, Berg JP, Mella B \& Husebye ES. Normal overall mortality rate in Addison's disease, but young patients are at risk of premature death. European Journal of Endocrinology 2009160 233-237. (https:// doi.org/10.1530/EJE-08-0550)

4 Burman P, Mattsson AF, Johannsson G, Hoybye C, Holmer H, Dahlqvist P, Berinder K, Engstrom BE, Ekman B, Erfurth EM et al. Deaths among adult patients with hypopituitarism: hypocortisolism during acute stress, and de novo malignant brain tumors contribute to an increased mortality. Journal of Clinical Endocrinology and Metabolism 201398 1466-1475. (https://doi.org/10.1210/jc.20124059)

5 Lovas K, Loge JH \& Husebye ES. Subjective health status in Norwegian patients with Addison's disease. Clinical Endocrinology 200256 581-588. (https://doi.org/10.1046/j.13652265.2002.01466.x)

6 Hahner S, Loeffler M, Fassnacht M, Weismann D, Koschker AC, Quinkler M, Decker O, Arlt W \& Allolio B. Impaired subjective health status in 256 patients with adrenal insufficiency on standard therapy based on cross-sectional analysis. Journal of Clinical Endocrinology and Metabolism 200792 3912-3922. (https://doi.org/10.1210/jc.20070685)

7 Kluger N, Matikainen N, Sintonen H, Ranki A, Roine RP \& SchalinJantti C. Impaired health-related quality of life in Addison's disease - impact of replacement therapy, comorbidities and socio-economic factors. Clinical Endocrinology 201481 511-518. (https://doi. org/10.1111/cen.12484)

8 Burger-Stritt S, Pulzer A \& Hahner S. Quality of life and life expectancy in patients with adrenal insufficiency: what is true and what is urban myth? Frontiers of Hormone Research 201646 171-183. (https://doi.org/10.1159/000443918)

9 Hahner S, Spinnler C, Fassnacht M, Burger-Stritt S, Lang K, Milovanovic D, Beuschlein F, Willenberg HS, Quinkler M \& Allolio B. High incidence of adrenal crisis in educated patients with chronic adrenal insufficiency: a prospective study. Journal of Clinical Endocrinology and Metabolism 2015100 407-416. (https://doi. org/10.1210/jc.2014-3191)

10 Reisch N, Willige M, Kohn D, Schwarz HP, Allolio B, Reincke M, Quinkler M, Hahner S \& Beuschlein F. Frequency and causes of adrenal crises over lifetime in patients with 21-hydroxylase deficiency. European Journal of Endocrinology 2012167 35-42. (https:// doi.org/10.1530/EJE-12-0161)

11 Ritzel K, Beuschlein F, Mickisch A, Osswald A, Schneider HJ, Schopohl J \& Reincke M. Clinical review: Outcome of bilateral adrenalectomy in Cushing's syndrome: a systematic review. Journal of Clinical Endocrinology and Metabolism 201398 3939-3948. (https:// doi.org/10.1210/jc.2013-1470)
12 Smans LC, Van der Valk ES, Hermus AR \& Zelissen PM. Incidence of adrenal crisis in patients with adrenal insufficiency. Clinical Endocrinology 201684 17-22. (https://doi.org/10.1111/cen.12865)

13 Hahner S, Loeffler M, Bleicken B, Drechsler C, Milovanovic D, Fassnacht M, Ventz M, Quinkler M \& Allolio B. Epidemiology of adrenal crisis in chronic adrenal insufficiency: the need for new prevention strategies. European Journal of Endocrinology 2010162 597-602. (https://doi.org/10.1530/EJE-09-0884)

14 Meyer G, Badenhoop K \& Linder R. Addison's disease with polyglandular autoimmunity carries a more than 2.5-fold risk for adrenal crises: German Health Insurance Data 2010-2013. Clinical Endocrinology 201685 347-353. (https://doi.org/10.1111/cen.13043)

15 Allolio B. Extensive expertise in endocrinology. Adrenal crisis. European Journal of Endocrinology 2015172 R115-R124. (https://doi. org/10.1530/EJE-14-0824)

16 Bornstein SR, Allolio B, Arlt W, Barthel A, Don-Wauchope A, Hammer GD, Husebye ES, Merke DP, Murad MH, Stratakis CA et al. Diagnosis and treatment of primary adrenal insufficiency: an Endocrine Society clinical practice guideline. Journal of Clinical Endocrinology and Metabolism 2016101 364-389. (https://doi. org/10.1210/jc.2015-1710)

17 Hahner S, Hemmelmann N, Quinkler M, Beuschlein F, Spinnler C \& Allolio B. Timelines in the management of adrenal crisis - targets, limits and reality. Clinical Endocrinology 201582 497-502. (https:// doi.org/10.1111/cen.12609)

18 Kampmeyer D, Lehnert H, Moenig H, Haas CS \& Harbeck B. A strong need for improving the education of physicians on glucocorticoid replacement treatment in adrenal insufficiency: an interdisciplinary and multicentre evaluation. European Journal of Internal Medicine 2016 33 e13-e15. (https://doi.org/10.1016/j.ejim.2016.04.006)

19 Harbeck B, Brede S, Witt C, Sufke S, Lehnert H \& Haas C. Glucocorticoid replacement therapy in adrenal insufficiency - a challenge to physicians? Endocrine Journal 201562 463-468. (https:// doi.org/10.1507/endocrj.EJ14-0612)

20 Burger-Stritt S, Kardonski P, Pulzer A, Meyer G, Quinkler M \& Hahner S. Management of adrenal emergencies in educated patients with adrenal insufficiency - a prospective study. Clinical Endocrinology 201889 22-29. (https://doi.org/10.1111/cen.13608)

21 White KG. A retrospective analysis of adrenal crisis in steroiddependent patients: causes, frequency and outcomes. BMC Endocrine Disorders 201919 129. (https://doi.org/10.1186/s12902-019-0459-z)

22 Chapman SC, Llahana S, Carroll P \& Horne R. Glucocorticoid therapy for adrenal insufficiency: nonadherence, concerns and dissatisfaction with information. Clinical Endocrinology 201684 664-671. (https://doi.org/10.1111/cen.12991)

23 Tiemensma J, Andela CD, Pereira AM, Romijn JA, Biermasz NR $\&$ Kaptein AA. Patients with adrenal insufficiency hate their medication: concerns and stronger beliefs about the necessity of hydrocortisone intake are associated with more negative illness perceptions. Journal of Clinical Endocrinology and Metabolism 201499 3668-3676. (https://doi.org/10.1210/jc.2014-1527)

24 Flemming TG \& Kristensen LO. Quality of self-care in patients on replacement therapy with hydrocortisone. Journal of Internal Medicine 1999246 497-501. (https://doi.org/10.1046/j.13652796.1999.00538.x)

25 Fleming LK, Rapp CG \& Sloane R. Caregiver knowledge and selfconfidence of stress dosing of hydrocortisone in children with congenital adrenal hyperplasia. Journal of Pediatric Nursing 201126 e55-e60. (https://doi.org/10.1016/j.pedn.2011.03.009)

26 Repping-Wuts HJ, Stikkelbroeck NM, Noordzij A, Kerstens M \& Hermus AR. A glucocorticoid education group meeting: an effective strategy for improving self-management to prevent adrenal crisis. European Journal of Endocrinology 2013169 17-22. (https://doi. org/10.1530/EJE-12-1094) 
27 White K \& Arlt W. Adrenal crisis in treated Addison's disease: a predictable but under-managed event. European Journal of Endocrinology 2010162 115-120. (https://doi.org/10.1530/EJE-09-0559)

28 Quinkler M, Ekman B, Zhang P, Isidori AM, Murray RD \& EU-AIR Investigators. Mortality data from the European Adrenal Insufficiency Registry-patient characterization and associations. Clinical Endocrinology 201889 30-35. (https://doi.org/10.1111/ cen.13609)
29 Rushworth RL \& Torpy DJ. A descriptive study of adrenal crises in adults with adrenal insufficiency: increased risk with age and in those with bacterial infections. BMC Endocrine Disorders 20141479. (https://doi.org/10.1186/1472-6823-14-79)

30 van der Meij NT, van Leeuwaarde RS, Vervoort SC \& Zelissen PM. Self-management support in patients with adrenal insufficiency. Clinical Endocrinology 201685 652-659. (https://doi.org/10.1111/ cen.13083)

Received 1 March 2020

Revised version received 22 April 2020

Accepted 6 May 2020 